\title{
Visual Art Learning in Virtual Community: A Study of Collaborative Learning in Hijabographic Community
}

\author{
Rahina Nugrahani \\ Art Department \\ Universitas Negeri Semarang, Indonesia \\ rahina_dkv@mail.unnes.ac.id
}

\author{
Triyanto \\ Art Department \\ Universitas Negeri Semarang, Indonesia \\ triyanto@mail.unnes.ac.id \\ Wandah Wibawanto \\ Art Department \\ Universitas Negeri Semarang Indonesia \\ wandah@mail.unnes.ac.id
}

\author{
Wan Juriah Emeih Binti Wahed \\ Art Education \\ Universiti Pendidikan Sultan Idris \\ Perak, Malaysia \\ amiesaiful@yahoo.com
}

\begin{abstract}
The dynamic of knowledge in the information era has created non-formal learners who are able to develop their own specific materials, methods, and learning strategies. This condition encourages the emergence of various virtual communities that produce mutual interaction. This article explores the collaborative visual art learning adapted by Hijabographic, a virtual community focused on developing Muslim women skills and knowledge in visual arts. The technique used to collect data in this study includes interviews involving founders and community members, observation and document tracking. This study finds that the collaborative learning models adapted in this virtual community are flexible, interactive and open to all available possibilities. The principle of flexibility makes learners in this community more active to build their own creativity and adaptive to face challenges in disruption era.
\end{abstract}

Keywords: virtual community, collaborative learning, disruption era, visual arts

\section{INTRODUCTION}

The changes that occurred in the era of disruption were very fundamental changes, in the form of a paradigm shift to make the leap forward. This is caused by changes in the development of science that results in innovation and invention in the acceptance, use and implementation of science and technology. Technology encourages a variety of changes, not only in technology itself but also in human life, the way humans relate, the way we organize including human ways to access education.

Arts education and learning face a situation where the change in various aspects of life, whether economic, social, political and cultural happened so fast. Compaction of production time and consumption distance causes people's trends and tastes are changing in a short time, and it also encourages the emergence of an instant attitude in defence (ephemerality). The education system, including in the field of art education, has not been able to anticipate the characteristics of the overall life acceleration [1]. The knowledge and skills offered through formal education are often far behind the demands and needs of the industry. This condition requires continuous renewal of knowledge in the education system, so that the gap between the education system and the development of science can be anticipated.

Arts education aims to inculcate aesthetic value by providing perceptual, cultural and artistic experiences [2]. Perceptual experiences instilled through the process of thinking, creation, imagination and creative expression. Cultural experience is obtained by learning and understanding both past and present cultural forms. Artistic experience is developed through understanding and improving skills by appreciating the artwork produced by others.

The existence of internet technology has opened access to achieve the goals of art education through non-formal learning spaces. Various information, articles, and learning resources can be obtained and accessed in a short time. Learners are allowed to think of various questions and can directly search for answers to these questions through search engines.

\section{PROBLEM STATEMENT}

Learning methods offered in classrooms are too slow for most students in the information technology era. The learning content obtained from formal education cannot always accommodate their needs in answering various questions and the specific skills they need to become individuals who are ready to compete in the technological era. Young learners always have curiosity and high enthusiasm for knowledge, now they have unimpeded access to any information they need to improve their knowledge and skills independently. In art, the learning process of various kinds of knowledge and skills is closely related to the demands of job and industry. The ability to absorb a number of information combined with an intuitive understanding of things that are relevant in each situation, is much faster than the learning curriculum offered by formal education. They do not always place themselves in a formal academic community, but prefer a community that can accommodate their interests in obtaining information that supports their skills and knowledge. Therefore, the trend to search for these two things, the knowledge and skills of artmaking, through non-formal education and using unconventional media is a phenomenon that occurs in era of technology.

This study aims to explain how collaborative visual art learning were adapted by Hijabographic, a virtual community that focuses on developing the skills and knowledge of Muslim women.

\section{VIRTUAL COMMUNITY}

The technological era is considered appropriate in accommodating constructivist educational perspectives 
which confirms that individuals will achieve their maximum potential better when they are actively involved in digging, exploring and sharing information held with other people in a community. Constructivist education encourages individuals to learn by exploring ideas and sharing their opinions with others [3]. This is one factor that causes learners in the millennial era to feel more comfortable to be in a virtual community.

Millennial are dominated by activities that demand the use of information and communication technology, where the use of web and smartphone based applications is natural for them. Participation in various types of interactions in virtual space produces a variety of visual media, audio, and produces high digital literacy. Learners in this digital age effectively accommodate the 'language' of new technology which has always been part of their daily experience [4]. Central characteristics in the interaction of virtual communities give learners the opportunity to broaden their experience. Interactivity using social media can explore complex ideas such as subject relations with technology that allows the subject to influence the production of objects, reverse subject-object relationships, and blur the boundaries between subject and object relations. The concept of interactivity in virtual communities is a key feature when we think about the learning concepts proposed by Dewey about activities and experiences [5].

The virtual world is a large-scale online community where virtual residents can share their beliefs, make new discoveries, and generate new ideas. Virtual communities have several advantages over the old-fashioned communities. Because virtual resident cannot see one another, people are unable to form prejudices about others before they read what they have to say: Race, gender, age, national origin and physical appearance are not apparent unless a person wants to make such characteristics public.Virtual world creating a community from a collection of strangers [6]. The reality built in it is actually not a reality but an intellectual creation. When it comes to aspects of education, internet technology is not only a medium that connects virtual communities but also becomes a wide learning space.

\section{METHODOLOGY}

This study aims to explain how collaborative art learning is adapted by Hijabographic, a virtual community that focuses on developing the skills and knowledge of Muslim women. The method used in this study is qualitative approach, which is intended to understand the phenomenon of what is experienced by research subjects, such as behavior, perception, motivation and overall action. The research stage is generally described in three main steps of qualitative research,[7] which includes; 1) Pre-field stage that is focused on designing research activities, determining informants and designing data collection techniques, 2) the second stage is data collection. The technique used in this stage are observation, interview and document tracking, 3) the final stage is the data analysis stage, where all valid data will be analyzed inductively using an interactive cycle model. The techniques used to collect data in this study include interviews, observation and document tracking. Data sources in this study are: (1) Hijabographic Founder, (2) Visual art professionals who have been involved in Hijabographic events and workshops as instructors, (3)
Hijabographic members who have participated in Hijabographic activities and workshops, (5 ) Documentation of members' work (6) Documentation of collaboration work between members

\section{HIJABOGRAPHIC AS VIRTUAL COMMUNITY}

Hijabographic is a Muslim women's community that has a mission to convey values in the Islamic religion through creative content by utilizing visual communication media. The main platform used by Hijabographic is social media such as Instagram and websites. This community was founded in 2013 by Riza Sativianti who has a scientific background in interior design. Supported by two co-founders with visual communication design background,

Hijabographic committed to be a creative place for Muslim women who present the message and value of da'wah through drawing, lettering, photography, crafts and other visual communication designs. According to Riza, the current number of Hijabographic members spread throughout Indonesia reaches more than 300 people across country.

Hijabographic is a virtual laboratory in gathering visual arts with da'wah. The beginning of the establishment of this community was motivated by the need to publish potential Muslim women's visual art works. According to Riza, so far Muslim women have various talents in artistic activities, but are reluctant to expose and express their potential. In addition, a community that can accommodate the needs of Muslim women to develop their creativity in performing artistic activities is very limited. Hijabographic provides opportunities and facilitates visual art creators to promote their work. Through this community, Muslim women who have passion and interest in visual arts can collaborate with each other, so that their work can be disseminated to provide greater benefits for other Muslim women. The collaboration between members generated various artworks e.g. comics, electronic posters, and various merchandise that are traded to support community activities or to support donations of social activities.

Through the process of interviewing, observing and tracking documents carried out, it is known that Hijabographic can be categorized as a community initiated, established and managed by its own members. This community can be referred to as membership-initiated virtual communities, where the orientation of this community is social and professional. This is in line with the classification of virtual communities conducted by Porter which states that membership initiated communities will generally be connected by orientations related to leisure activities, hobbies or professionals of interest or other nonprofessional interests [8]. In the case of the Hijabographic community, the most prominent orientation and binding on solidarity among members is Islamic value and the purpose of da'wah.

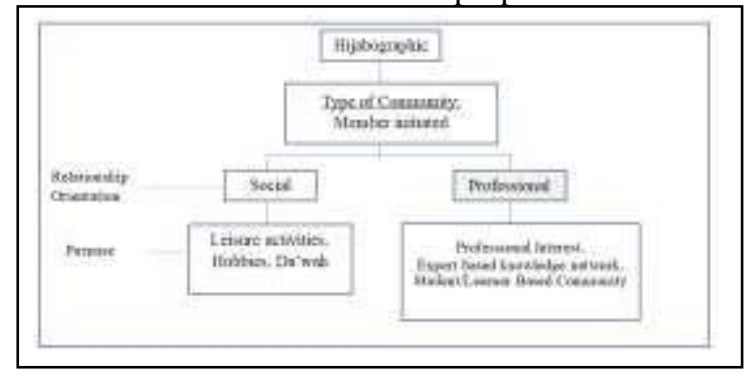

Figure 1. Hijabographic positioning as a virtual community 


\section{COLLABORATIVE LEARNING IN HIJABOGRAPHIC}

Hijabographic community consists of Muslim women from various educational, occupational and cultural backgrounds. Based on interview results to 50 members of Hijabographic, it is known that members of this community consist of professionals in the field of visual arts, entrepreneurs, visual arts students/academicians, and hobbyists. Members who join Hijabographic community are aged between 18 and 38 years old.

Some members do not have formal visual arts education background, and are not involved in the visual arts industry. Members' interest in joining the community is due to their religious orientation and passion for da'wah by utilizing visual art as their medium. The biggest motivation of members to join Hijabograhic community is based on a common vision to spread Islamic values through visual communication media.

Community activities are carried out online, for example, Daily Artwork, Artwork Chalenge and Hijabotalks. Daily artwork is a feature to publish members' work through hijabographic official account in Instagram. Artwork Chalenge is an activity aimed at Muslim women to pump up the spirit of work which is framed in one specific theme. For example, before the independence day of the Republic of Indonesia, a challenge was held to produce work on the theme of the independence day. On another occasion, the challenges given by Hijabographic coincided with the coming of the month of Ramadan, where members were challenged to produce work about improving the quality of worship during Ramadan.
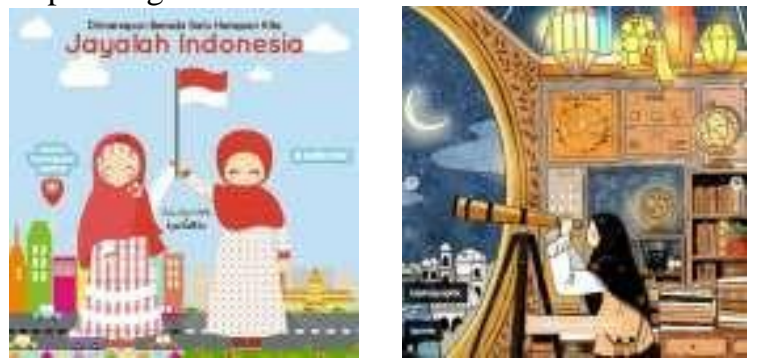

Figure 2. Members' artworks, responding Artwork Challenge activities

Hijabotalks is an online discussion activity managed by Hijabographic crew where members have the opportunity to discuss with artists or professionals. These activities can be a trigger in order to increase the enthusiasm of members to be more productive in creating visual arts.

Online discussion activities utilizing the "Ask me Question", "Live Streaming" and IGTV features in Instagram features are used by Hijabographic to bridge members to interact with professionals in the visual arts. In addition, experts can also upload various tutorials on new techniques and media in IGTV. Even the idea of presenting collaborative visual artwork can emerge from online discussions, i.e. a comic entitled HijaboComic which published in 2014. This comic is a collaboration between illustrators, story writers, layout designers who are members of the Hijabographic community.

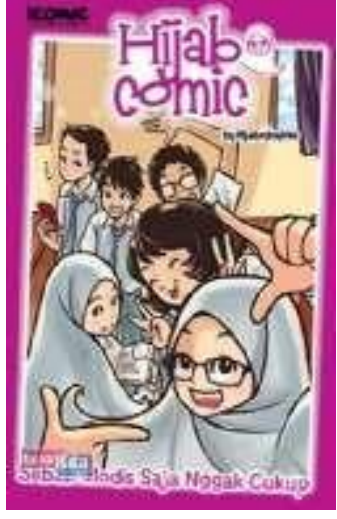

Figure3. Hijabocomic as one of the result of collaborative artwork

All features contained in social media become a space for members to share and learn. This online discussion activity is considered more effective because it can minimize the constraints related to location and time. Members, wherever and whenever they are, can easily participate in activities held online because Hijabographic utilizes social media platforms that are very close to the daily activities of members. This is in line with the opinion stated by Munteanu et.al that new technologies, such as social media, - which are judiciously implemented in arts learning - promote experiential learning, stimulate the learners 'interrogative spirits and combine the independent work within the participants' work group [9].

Interaction built between members in this community is not only online, but also offline activities that accommodate face-to-face meetings between members. The offline activities were carried out in Hijaboclass which facilitated member meetings through creative workshop activities aimed to enhance the ability of Muslim women to produce visual arts. Hijabographic invites experts or professionals who master specific art work skills. Experts or professionals who become instructors in workshop activities are mostly community members.

The workshops held in recent years included workshops on modern calligraphy, shibori, paper craft, and drawing with watercolor media. Hijaboclass activities are carried out regularly in several major cities in Indonesia such as Jakarta, Bandung and Yogyakarta.

All online and offline activities carried out by Hijabographic are published regularly using social media. Maximizing Instagram features to publish member's works and community recent activities have been effective in attracting audiences with a wider scope to follow the updated posts made by Hijabographic. Instagram is also an effective medium for defining Hijabographic positioning as a community for Muslim women. Through Instagram, audience can analyze the temporal image sharing pattern which can be a good indicator about cultural behaviors, and also says a lot about certain classes of places and activities [10].

The finding of this study shows that all members of this community have the same opportunity to improve visual arts learning and knowledge. All members have the opportunity to play a role, both as learners and as instructors. The wide range of visual art fields accommodated by this community includes drawing, painting, printmaking, design, crafts, and photography, 
which provides opportunities for all members to master more than one specific skill. Through these skills, community members strive to spread Islamic values to inspire others. The spirit in da'wah becomes a bond between members which causes this community to be solid, to continue in making inspiring movements for other Muslim women through visual communication work.

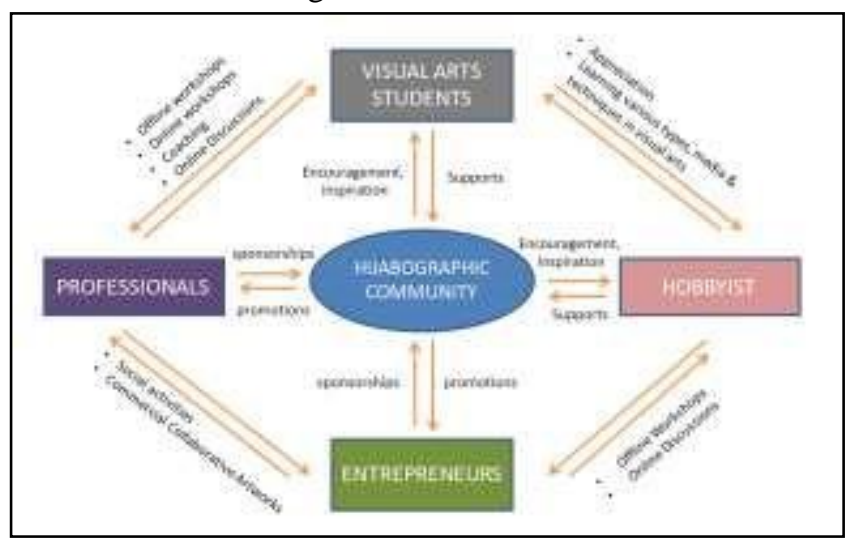

Figure4. Patterns of interaction among memmbers that produce collaborative learning in the community

\section{CONCLUSIONS}

Collaborative learning in Hijabographic community has produced a considerable interaction where all members help and encourage each other to learn. They do this by explaining what they understand and by gathering and sharing knowledge. Community members' collaborative works must be done interactively providing one another with feedback, challenging one another's conclusions and reasoning, and perhaps most importantly, teaching and encouraging one another [11]. Members in the community can directly carry out two functions, either as participants or as learning instructors. The substitution of member roles in the community becomes so flexible and adaptive.

Existing technologies and virtual environments offering different learning potentials and specific pedagogical design criteria. In a constructivist learning style, the instructional design must be begin from the pedagogical affordances of the specific environment. Virtual community are able to provide their classes to the appropriate degree of difficulty, stimulate creativity, encourage knowledge sharing, develop case studies, and enable the establishment of evaluation criteria [12]. A sense of belonging makes members of the community have the responsibility to do part of their work Hijaboclass has fulfilled three main aspects of art learning which aim to instill aesthetic values among members, i.e. 1) perceptual aspects that facilitate members to think critically, create, imagine and get creative experience, 2) cultural aspects that facilitate members to learn local wisdom gained from interactions between members who have different cultural backgrounds, 3) artistic aspects obtained through the process of producing and appreciating the work between members .

Hijabographic as a virtual community becomes a suitable learning space for millennial learners who are independent, flexible and adaptive. Various outputs of activities produced by this community indicate that in exploring information that supports skills and knowledge in visual arts, can be achieved not only through formal education. Virtual communities can accommodate member's interests to explore the specific skills and knowledge needed. This virtual community shows a way to organize a large number of people with a variety of educational, cultural and age backgrounds to contribute to each other, in order to improve their ability and knowledge in the visual arts. There is a division of authority and acceptance of responsibilities among group members to organize activities conducted online and offline.

\section{REFERENCES}

[1] Y. A. Piliang, Dunia Yang Berlari, Second Edi. Yogyakarta: Aurora, 2017.

[2] Triyanto, Spirit Ideologis Pendidikan Seni, First Edit. Semarang: Cipta Prima nusantara, 2017.

[3] E. Nurhidayati, "Pedagogi Konstruktivisme Dalam Praksis Pendidikan Indonesia," Indones. J. Educ. Couns., vol. 1, no. 1, pp. 1-14, 2017.

[4] J. Grenfell, "Immersive interfaces for art education teaching and learning in virtual and real world learning environments .," Procedia - Soc. Behav. Sci., vol. 93, pp. 1198-1211, 2013.

[5] K. A. Peppler, "Media Arts : Arts Education for a Digital Age," Teach. Coll. Rec., vol. 112, no. 8, pp. 2118-2153, 2010.

[6] H. Rheingold, "Virtual communities - exchanging ideas through computer bulletin boards," J. Virtual Worlds Res., vol. 1, no. 1, pp. $1-5,2008$

[7] L. J. Moleong, Metode Penelitian Kualitatif. Bandung: Rosdakarya, 2006.

[8] C. E. Porter, "A Typology of Virtual Communities: A MultiDisciplinary Foundation for Future

Research," J. Comput. Commun., vol. 10, no. 1, pp. 01-30, 2006.

[9] L. Munteanu, G. Gorghiu, and L. Monica, "The Role of New Technologies for Enhancing Teaching and Learning in Arts Education," Procedia - Soc. Behav. Sci., vol. 122, no. 122 (2014), pp. 245-249, 2014.

[10] T. H. Silva, P. O. S. V. de Melo, J. M. Almeida, J. Salles, and A. A. F. Loureiro, "A Picture of Instagram is Worth More Than a Thousand Words: Workload Characterization and Application," 2013 IEEE Int. Conf. Distrib. Comput. Sens. Syst., no. i, pp. 123$132,2013$.

11] M. Laal and M. Laal, "Collaborative learning: What is it?," Procedia - Soc. Behav. Sci., vol. 31, no. December 2012, pp. 491495, 2012.

[12] L. Stefan, "Immersive collaborative environments for teaching and learning traditional design," Procedia - Soc. Behav. Sci., vol. 51, no. 51(2012), pp. 1056-1060, 2012. 